\title{
KUALITAS HIDUP PASIEN GAGAL JANTUNG KONGESTIF (GJK) BERDASARKAN KARAKTERISTIK DEMOGRAFI
}

\author{
Arif Nur Akhmad ${ }^{1}$, Yanuar Primanda 2 , Yuni Permatasari Istanti ${ }^{3}$
}

\author{
1 Master Students, Graduated Institute of Nursing, \\ Central Taiwan University of Science and Technology. \\ 23 Dosen Keperawatan Medikal Bedah, Program Studi Ilmu Keperawatan, \\ Fakultas Kedokteran dan IImu Kesehatan, Universitas Muhammadiyah Yogyakarta. \\ email: nersarif1992@yahoo.co.id
}

\begin{abstract}
Patients of Congestive Heart Failure (CHF) basically have some symptoms, such as fatigue, dyspnea, and high mortality contributing to affects on their quality of life. Various factors may be related to quality of life, such as age, gender, education, occupation, and NYHA (New York Heart Association) level. This research aims at identifying and explaining demography factors related to quality of life on Congestive Heart Failure (CHF) patients. This research uses descriptive correlation and cross sectional design with 62 patients of Dr. Sardjito Hospital Yogyakarta as the sample. Data obtained by using demographic data questionnaire and the SF-36 version of Indonesian. Data were analyzed with Spearman's test. The results showed respondents with a median age 51.14 years $(S D=12.40)$. Most patients are male $(71 \%)$, unemployed $(69 \%)$. and less educated $(53 \%)$. Quality of life has correlation with NYHA class ( $p$ value $=0,001$ ), educational ( $p$ value $=0,001)$, and age ( $p$ value $=0,014)$. There is no correlation between quality of life and gender and occupation. It can be concluded that NYHA class, educational, and age are independent factors related to quality of life.
\end{abstract}

Keyword: Congestive Heart Failure (CHF), Quality of Life, demographic

\section{ABSTRAK}

Pasien gagal jantung kongestif (GJK) mengalami kelelahan dan dyspnea yang berkontribusi memperburuk kualitas hidupnya. Berbagai faktor demografi yang berkaitan dengan kualitas hidup diantaranya umur, jenis kelamin, pekerjaan, pendidikan, dan derajat NYHA (New York Heart Assosiation). Tujuan penelitian ini adalah untuk mengidentifikasi dan menganalisis kualitas hidup berdasarkan data demografi pasien gagal jantung kongestif (GJK). Desain penelitian adalah deskriptif korelasi secara cross sectional dengan jumlah sampel sebanyak 62 responden yang diperoleh dengan cara purposive sampling. Data diperoleh dengan menggunakan kuisioner data demografi dan SF-36 versi bahasa Indonesia. Data dianalisis dengan uji Spearman. Hasil penelitian menunjukkan responden rata-rata berusia 51,14 tahun $(S D=12,40)$. Sebagian besar pasien berjenis kelamin laki-laki $(71 \%)$, memiliki pekerjaan $(69 \%)$. dan berpendidikan rendah (53\%). Kualitas hidup memiliki hubungan dengan pendidikan $(p=0,001)$, umur $(p=0,014)$, sedangkan kualitas hidup memiliki perbedaan dengan derajat menurut NYHA $(p=0,001)$. Tidak ditemukan hubungan antara kualitas hidup dengan jenis kelamin, dan pekerjaan. Penelitian ini menyimpulkan bahwa derajat menurut NYHA, pendidikan, dan umur merupakan faktor independen yang berkaitan dengan kualitas hidup.

Kata Kunci: demografi, Gagal Jantung Kongestif (GJK), Kualitas Hidup 


\section{PENDAHULUAN}

Gagal jantung menjadi penyakit yang umum diderita di dunia. Sekitar lima juta orang di Amerika Serikat menderita gagal jantung kongestif (GJK), dimana jumlah tersebut didominasi oleh orang tua, dengan hampir $80 \%$ kasus terjadi pada pasien di atas usia 65 tahun. Namun demikian, beberapa studi telah menemukan bahwa GJK dikaitkan dengan angka kematian sekitar $45-50 \%$ selama kurun waktu dua tahun terakhir, jumlah ini mendekati angka kematian yang disebabkan oleh penyakit keganasan (O'Connor et al, 2009).

Prevalensi kasus gagal jantung kongestif di Indonesia terutama di Yogyakarta sebanyak 3.459 orang pada tahun 2012 dengan pasien rawat inap yang mengalami GJK sebanyak 401 orang. Berbagai terapi seperti terapi farmakologi dan non farmakologi hanya mampu mengurangi gejala pada gagal jantung kongestif, sehingga akan mempengaruhi kualitas hidup pasien (Raghu et al, 2010; Dimos et al, 2009).

Kualitas hidup pasien dengan GJK dipengaruhi oleh beberapa faktor yaitu umur, jenis kelamin, pekerjaan, pendidikan, dan derajat NYHA (New York Heart Assosiation). Umur dan jenis kelamin merupakan faktor yang sangat penting pada pasien GJK. Semakin bertambah tua umur seseorang, maka penurunan fungsi tubuh akan terjadi baik secara psikologis maupun fisik (Nurchayati, 2011). Begitu juga dengan jenis kelamin, pria lebih cenderung memiliki kemampuan fungsi tubuh yang lebih baik daripada wanita terutama fisik (Juenger et al, 2002). Dampak dari kemampuan fungsi fisik yang menurun akan mempengaruhi derajat GJK seseorang.
Menurut NYHA, GJK dibagi berdasarkan 4 derajat kemampuan fisik. Derajat I menunjukkan seseorang bisa beraktifitas secara normal, pada derajat II pasien menunjukan gejala ringan saat melakukan aktivitas sehingga pasien merasa lebih nyaman bila beristirahat, pada derajat III pasien sudah mulai menunjukan adanya keterbatasan fisik, dan pada derajat IV pasien sudah tidak bisa melakukan aktivitas apapun tanpa keluhan (O'Connor et al, 2009). Kondisi tersebut akan mempengaruhi sejauh mana pasien mampu memaksimalkan fisiknya, sehingga mempengaruhi kualitas hidup pasien. Faktor tersebut juga dipengaruhi tingkat pendidikan dan pengetahuan seseorang dalam mengenal masalahnya (Ose et al., 2014).

Tingkat pendidikan dan pengetahuan merupakan faktor yang berkaitan dengan kualitas hidup pasien GJK (Rognerud \& Zahl5 f cd, 2006). Pasien yang memiliki tingkat pendidikan yang lebih tinggi akan mudah untuk mendapatkan informasi terkait kondisi yang sedang dialami, maupun menganalisis masalah yang akan timbul, serta bagaimana mengatasi masalah tersebut (Nurchayati, 2011). Semakin tinggi tingkat pengetahuan seseorang maka akan semakin baik dalam memilih tindakan terapi yang tepat dalam pemulihan kondisinya sehigga kualitas hidup pasien juga akan meningkat (Van Der et al, 2006).

Tujuan dari studi ini yaitu untuk mengidentifikasi dan menganalisis kualitas hidup berdasarkan data demografi pasien gagal jantung kongestif (GJK) di RSUP Dr. Sardjito yogyakarta.

\section{METODE PENELITIAN}

Metode penelitian yang digunakan dalam penelitian ini adalah deskriptif korelasi 
dengan menggunakan pendekatan cross sectional study yang dilaksanakan di poliklinik jantung RSUP Dr. Sardjito Yogyakarta dengan waktu yang digunakan selama 2 bulan yaitu Mei-Juli 2013. Tehnik pengambilan sampel menggunakan purposive sampling dengan jumlah sampel yang digunakan dalam penelitian ini yaitu sebesar 62 responden dengan kriteria umur $\geq 35$ tahun, dan terdiagnosis GJK berdasarkan catatan medis pasien. Sebelum dilakukan penelitian, peneliti sudah melakukan ethical clearence di fakultas kedokteran Universitas Gajah Mada, Yogyakarta sehingga penelitian ini bisa dilaksanakan.

Instrument penelitian yang digunakan pada penelitian ini berupa kuesioner data demografi, dan kuisioner kualitas hidup (SF-36) versi indonesia yang diterjemahkan oleh Saryono (2010). Statistik yang digunakan meliputi distribusi frekuensi untuk analisis data demografi dan uji Spearman, uji ini digunakan untuk mengetahui hubungan antara variabel independen dan dependen.

\section{HASIL}

\section{Karakteristik Demografi}

Karakteristik demografi responden adalah sebagai berikut: umur responden ratarata (mean) sebesar 51,14 $(S D=12,40)$ yang terdistribusi normal ( $p$-value= $0,200)$. Umur termuda adalah 30 tahun dan umur tertua adalah 74 tahun. Sebagian besar responden berjenis kelamin laki-laki yaitu 44 orang $(71 \%)$, sedangkan sisanya yaitu 18 orang (29\%) berjenis kelamin perempuan. Responden yang bekerja lebih banyak yaitu 43 orang (69 \%) dibandingkan dengan yang tidak bekerja yaitu 19 orang (31\%). Tingkat pendidikan sebagian besar responden berpendidikan rendah 33 orang $(53 \%)$.
Tabel 1: Derajat GJK dan Kualitas Hidup $(\mathrm{N}=62)$

\begin{tabular}{lc}
\hline Variabel & $\mathbf{n}(\%)$ \\
\hline Derajat GJK & \\
Derajat 1 & $28(45,2)$ \\
Derajat 2 & $25(40,3)$ \\
Derajat 3 & $8(12,9)$ \\
Derajat 4 & $1(1,6)$ \\
& \\
Kualitas & Mean (SD): \\
Hidup & $56,91(14,43) ;$ \\
& Range: \\
& $28-88$ \\
\hline
\end{tabular}

\section{Derajat GJK menurut NYHA (New York Heart Assosiation).}

Sebagian besar responden gagal jantung kongestif (GJK) adalah derajat 1 menurut NYHA sebesar 28 responden $(45,2 \%)$, derajat 2 sebesar 25 responden $(40,3 \%)$, derajat 3 sebesar 8 responden $(12,9)$, dan derajat 4 sebesar 1 responen $(1,6 \%)$ dengan distribusi data tidak normal $(p-$ value $=0,000$ ).

\section{Kualitas Hidup}

Kualitas hidup responden rata-rata (mean) sebesar 56,91 (SD= 14,43) yang terdistribusi normal ( $p$-value $=0,200$ ). Kualitas hidup terendah bernilai 28 dan kualitas hidup tertinggi bernilai 88 .

\section{Hubungan antara Umur dan Kualitas Hidup}

Terdapat hubungan yang signifikan antara umur dengan kualitas hidup $(r=-$ 0,311, p-value $=0,014)$. Besaran koefisien determinan umur sebesar 0,096 $(9,6 \%)$, berarti umur menentukan $9,6 \%$ kualitas hidup, sedangkan sisanya $90,4 \%$ ditentukan oleh faktor lain. Arah hubungan bersifat negatif, artinya bahwa semakin bertambah umur maka kualitas 
Tabel 2. Hubungan Karakteristik Demografik Pasien dan Kualitas Hidup

\begin{tabular}{lll}
\hline $\begin{array}{l}\text { Karakteristik } \\
\text { Pasien }\end{array}$ & KH & $\boldsymbol{p}$ \\
\hline Umur & $-0,311^{*}$ & 0,014 \\
Jenis Kelamin & $-0,194$ & 0,131 \\
Pendidikan & $0,397^{*}$ & 0,001 \\
Pekerjaan & 0,075 & 0,561 \\
\hline
\end{tabular}

hidup semakin menurun.

\section{Hubungan antara Jenis Kelamin dan Kualitas Hidup.}

Hasil uji statistik antara Jenis kelamin dengan kualitas hidup diperoleh nilai $p$ value $=0,131 \quad(r=-0,194)$ yang menunjukan bahwa hubungan antara jenis kelamin dengan kualtas hidup adalah tidak bermakna dengan arah hubungan bersifat negatif.

\section{Hubungan antara pendidikan dengan kualitas hidup.}

Hasil uji statistik antara pendidikan dengan kualitas hidup diperoleh nilai $p$ value $=0,001 \quad(r=0,379)$ yang menunjukan bahwa hubungan antara pendidikan dengan kualtas hidup adalah bermakna. Arah hubungan bersifat positif yang berarti semakin tinggi pendidikan maka semakin baik kualitas hidup pasien.

\section{Hubungan antara Pekerjaan dan Kualitas Hidup}

Hasil uji statistik antara pendidikan dengan kualitas hidup diperoleh nilai $p$ value $=0,561 \quad(r=0,075)$ yang menunjukan bahwa hubungan antara pekerjaan dengan kualtas hidup adalah tidak bermakna dengan arah hubungan bersifat positif.
Tabel 3. Perbedaan Kualitas Hidup Berdasar Derajat GJK ( $\mathrm{N}=62)$

\begin{tabular}{llllll}
\hline $\begin{array}{l}\text { Derajat } \\
\text { GJK }\end{array}$ & Mean & SD & SE & F & p \\
\hline 1 & 2.265 & 495 & 93 & 6,561 & 0,00 \\
2 & 1.979 & 549 & 109 & & \\
3 & 1.488 & 341 & 120 & & \\
4 & 1.015 & - & - & & \\
\hline
\end{tabular}

\section{Perbedaan antara derajat GJK dan Kualitas Hidup}

Hasil analisis menggambarkan bahwa rata-rata kualitas hidup yang paling rendah adalah yang mempunyai derajat 4 menurut NYHA $(1,01 \%)$ dan yang paling tinggi adalah derajat 1 menurut NYHA $(2,26 \%)$. Analisis statistik menggambarkan bahwa terdapat perbedaan yang signifikan antara derajat NYHA dengan kualitas hidup ( $p$-value= $0,001, a=0,005$ ).

\section{PEMBAHASAN}

\section{Kualitas hidup}

World Health Organization (WHO) mendefinisikan kualitas hidup sebagai persepsi individu terhadap posisi mereka dalam kehidupan pada konteks budaya dan nilai dimana mereka hidup dalam hubunganya dengan tujuan hidup, harapan, standar, dan perhatian (Dunderdale et al, 2005). Konsep yang sangat luas ini mempengaruhi kesehatan fisik seseorang, keadaan psikologi, tingkat ketergantungan, hubungan sosial, keyakinan personal, dan keinginan di masa yang akan datang terhadap lingkungan sekitarnya (Isa \& Baiyewu, 2006).

Penelitian ini didapatkan hasil bahwa rata-rata kualitas hidup pasien sebesar 56,91. Pada responden dalam penelitian ini sebagian besar mendapatkan biaya untuk berobat dari 
Askes atau Jamkesmas, ditinjau dari pola komunikasi dan presepsi diri sebagian besar baik dan tanpa keluhan yang mengganggu. Dengan adanya dukungan yang baik dari segi finansial, presepsi diri yang baik serta tanpa keluhan yang mengganggu dapat membantu mengurangi gangguan psikologis akibat penyakit gagal jantung kongestif (GJK) ini, sehingga kualitas hidup responden meningkat.

Berbeda halnya dengan penelitian yang telah dilakukan oleh Lee et al (2005) di rumah sakit umum di Hong Kong, China dengan jumlah sample (N) sebesar 227 responden. Hasilnya menunjukkan bahwa rata-rata (mean= $16,78 \pm 3,44$ ) pasien gagal jantung kongestif memiliki kualitas hidup rendah, dengan gangguan psikologis merupakan faktor yang paling mempengaruhi kualitas hidup pasien ( $p$ value $=0,000)$. Hal tersebut menunjukkan bahwa gangguan psikologis yang meningkat dapat memperburuk kualitas hidup pasien GJK di china.

Perbedaan hasil penelitian ini dengan yang dilakukan oleh peneliti yaitu terdapat pada kondisi derajat GJK menurut NYHA. Menurut penelitian Lee et al (2005) mengatakan bahwa dominan pasien GJK yang memiliki derajat II menurut NYHA sebesar 49, 8 \% lebih tinggi jumlahnya dan tingkat derajatnya dibandingkan yang dilakukan peneliti yaitu $45,2 \%$ dengan dominan pasien memiliki derajat I menurut NYHA. Dari perbandingan ini membuktikan bahwa derajat NYHA sangat berhubungan dengan kualitas hidup pasien.

\section{Faktor-Faktor yang Berkaitan dengan Kualitas Hidup}

Umur. Pada penelitian ini didapatkan hasil bahwa umur memiliki hubungan dengan kualitas hidup ( $p$ value $=0,014$ ). Hal tersebut sesuai dengan teori yang mengatakan bahwa fungsi jantung akan berubah bersamaan dengan pertambahan usia. Pada lansia berumur 40 tahun keatas yang tidak aktif, jantung kirinya mengalami pengecilan sebagai respon terhadap rendahnya beban kerja yang dibutuhkan (Smeltzer et al, 2008). Terbukti bahwa pasien yang berumur rata-rata (mean) umur pasien lebih dari 51,14 tahun.

Heo et al (2009) juga mengatakan bahwa penuaan dapat mengakibatkan penurunan elastisitas dan pelebaran aorta, penebalan dan kekakuan katup jantung, serta peningkatan jaringan ikat yang mengakibatkan terjadinya gagal jantung pada manula.

Penelitian terbaru yang dilakukan oleh Banerjee et al (2013) pada 423 pasien yang mengalami gagal jantung membuktikan bahwa faktor umur berpengaruh secara signifikan $(p$ value $=$ 0,001 ) sebesar $54 \%$ terhadap kualitas hidup. Hal ini membuktikan bahwa faktor umur mempengaruhi kualitas hidup pasien.

Pendidikan. Berdasarkan pendidikan pasien, pasien yang memiliki pendidikan rendah sebanyak 33 orang (53\%) dan berpendidikan tinggi sebanyak 29 orang (47\%). Hasil penelitian ini didukung dengan teori dimana pengetahuan atau kognitif merupakan domain yang sangat penting untuk terbentuknya suatu tindakan, perilaku yang didasari pengetahuan akan lebih langgeng daripada yang tidak didasari pengetahuan (Notoadmodjo, 2007).

Azwar (2005) mengatakan bahwa semakin tinggi tingkat pendidikan 
seseorang maka dia akan cenderung untuk berperilaku positif karena pendidikan yang diperoleh dapat menjadi dasar pemahaman seseorang terhadap kebutuhan akan informasi terkait self management pasien dan perilaku mencari pelayanan kesehatan yang tepat. Penelitian yang dilakukan secara randomized controlled trial (RCT) pada 540 responden dengan gagal jantung membuktikan bahwa program edukasi mengenai monitor gejala, aktifitas fisik, dan penggunaan obat terbukti efektif dalam self management pasien yang sedang menjalankan rehabilitasi (Meng et al., 2013).

Derajat GJK menurut NYHA. Pasien yang mengalami gagal jantung kongestif memiliki gejala seperti rasa cepat lelah, sesak napas, takipnea dan takikardi. Kondisi fisik ini sangat mempengaruhi kemampuan dan fungsi pasien sehingga akan sangat mempengaruhi kualitas hidup pasien. (Arroll et al, 2010) Hal ini dibuktikan dengan hasil penelitian ini yang menyatakan secara signifikan ( $p$-value= 0,001 ) bahwa derajat gagal jantung kongestif menurut New York Heart Assotiation (NYHA) mempengaruhi kualitas hidup pasien.

Hasil ini di dukung penelitian yang dilakukan oleh Juenger et al (2002) yang membuktikan secara signifikan $(0,0001)$ bahwa kualitas hidup pasien dipengaruhi oleh derajat gagal jantung kongestif menurut NYHA pada 205 pasien di Jerman. Pada pasien GJK, fungsi fisik sangat berperan sebanyak $51 \%$ terhadap derajat menurut NYHA, dikarenakan apabila fungsi fisik tidak bisa digunakan secara optimal ,maka secara otomatis aktivitas fisik akan berkurang yang menyebabkan menurunya kualitas hidup pasien.
Dari hasil data distribusi responden yang dilakukan oleh peneliti didapatkan bahwa derajat 1 lebih banyak diderita oleh pasien di RSUP Dr. Sardjito Yogyakarta yaitu sebesar 45,2\%. Hal ini dikarenakan sebagian besar pasien berobat dan treadmill secara rutin sehingga kondisi fisik pasien tetap terjaga dan berfungsi secara makaimal yang membuat kualitas hidup pasien menjadi lebih baik.

\section{KESIMPULAN}

Faktor-faktor yang berhubungan dengan kualitas hidup adalah umur, pendidikan dan derajat GJK. Umur memiliki hubungan negatif terhadap kualitas hidup yang menyatakan bahwa semakin bertambahnya umur seseorang maka kualitas hidupnya akan menurun. Pendidikan memiliki hubungan positif terhadap kualitas hidup yang menyatakan bahwa semakin tinggi pendidikan pasien maka semakin baik kualitas hidup pasien. Derajat menurut NYHA memiliki perbedaan yang signifikan terhadap kualitas hidup pasien gagal jantung kongestif (GJK). Faktor yang tidak berhubungan dengan kualitas hidup adalah jenis kelamin, dan pekerjaan.

\section{UCAPAN TERIMA KASIH}

Dengan selesainya penelitian ini penulis mengucapkan terima kasih kepada RSUP Dr. Sardjito yang telah memfasilitasi terselenggaranya penelitian ini.

\section{DAFTAR PUSTAKA}

Arroll, B., Doughty, R., and Andersen, V. (2010). Investigation and management of congestive heart failure, BMJ, 341, pp.190-195. 
Azwar, S. (2005). Sikap Manusia dan Pengukurannya, Pustaka Setia, Jakarta.

Banerjee, T, Lee, K.S., Browning, S.R., Hopenhayn, C., Westneat, S., et al. (2013). Limited Association Between Perceived Control and Heald Related Quality of Life in Patient With Heart Failure, Journal of Cardiovascular Nursing, pp.1-5.

Dimos, A.K., Stougiannos, P.N., Kakkavas, A.T., and Trikas, A.G. (2009). Depression And Heart Failure. Hellenic J Cardiol, 50, pp.410-417.

Dunderdale, K., Thompson, D.R., Miles, J.N.V., Beer, S.F., and Furze G. (2005). Quality-of-life measurement in chronic heart failure: do we take account of the patient perspective?. The European Journal of Heart Failure, pp.572- 582.

Heo, S., Lennie, T. A., Okoli, C., \& Moser, D. K. (2009). Quality of Life in Patients With Heart Failure: Ask the Patients, Heart Lung, 38(2), pp.100108.

Isa, B.A., and Baiyewu, O. (2006). Quality Of Life Patient With Diabetes Mellitus In A Nigerian Teacihng Hospital, Hongkong Journal Psychiatry, 16, pp.27-33.

Juenger, J., Schellberg, D., Kraemer, S., Haunstetter, A., Zugck, C., Herzog, W., and Haass, M. (2002). Health Related Quality Of Life In Patients With Congestive Heart Failure: Comparison With Other Chronic Diseases And Relation To Functional Variable, Heart Journal, 87, pp.235241.

Lee, D.T.F., Yu, D.S.F., Woo, J., and Thompson, D.R. (2005). Healthrelated quality of life in patients with congestive heart failure. The
European Journal of Heart Failure, pp.419- 422.

Meng, K., Musekamp, G., Seekatz, B., Glatz, J., Karger, G., Kiwus, U., . . . Faller, H. (2013). Evaluation of a selfmanagement patient education program for patients with chronic heart failure undergoing inpatient cardiac rehabilitation: study protocol of a cluster randomized controlled trial. BMC Cardiovasc Disord, 13, 60. doi: 10.1186/1471-2261-13-60

Notoadmodjo, S. (2007). Promosi Kesehatan dan IImu Perilaku, Jakarta, PT. Rineka Cipta.

Nurchayati, S. (2011). Analysis of Factors Related to Quality of Life of Patients With Chronic Kidney Disease Undergroing Hemodialysis at the Islamic Hospital Fatimah Cilacap and Banyumas District General Hospital, Thesis Magister Keperawatan, Universitas Indonesia.

O'Connor, C.M., Whellan, D.J., Lee, K.L., Keteyian, S.J., Cooper, L.S., et al. (2013). Efficacy and Safety of Exercise Training in Patients With Chronic Heart Failure: HF-ACTION Randomized Controlled Trial, JAMA, 301 (14), pp.1439-1450.

Ose, D., Rochon, J., Campbell, S. M., Wensing, M., Freund, T., van Lieshout, J., ... Ludt, S. (2014). Health-related quality of life and risk factor control: the importance of educational level in prevention of cardiovascular diseases. Eur J Public Health, 24(4), 679-684. doi: 10.1093/eurpub/ckt139

Raghu, K.V., Srinivas. V, Kishore, B.A.V., Mohanta, G.P., and Uma, R.R. (2010). A Study on Quality of Life of Patients with Congestive Cardiac Failure. Indian Journal of Pharmacy Practice, 3, pp.33-39. 
Rognerud, M.A., and Zahl, P.H. (2006). Social inequalities in mortality: changes in the relative importance of income, education and household size over a 27 -year period. Eur J Public Health, 16:62-8.

Saryono. (2010), Kumpulan Instrumen Penelitian Kesehatan, Nulia Medika, Yogyakarta.

Smeltzer, S.C., Bare, B.G., Hinkle, J.L., and Cheever, K.H., (2008). Textbook of medical- surgical nursing. $12^{\text {th }} \mathrm{Ed}$, Wolter Kluwer, Lippincott William \& Wilkins.

Van der wal, M.H.L., Jaarsma, T., Moser, D.K., and Veeger, N.J.G.M., (2006). Compliance in heart failure patients: the importance of knowlege and beliefs, European Heart Journal, 27, 434-440. 